\title{
BƯớC ĐẦU XÁC ĐỊNH HÀM LƯợNG MỘT SỐ KIM LOẠI NẶNG TRONG MÔI TRƯỜG NƯỚC SÔNG HỒNG
}

\author{
Nguyễn Thị Bích Ngọc ${ }^{1}$, Lê Thị Phương Quỳnh ${ }^{1, *}$, Nguyễn Thị Mai Hương", \\ Nguyễn Bích Thủy ${ }^{1}$, Vũ Duy An ${ }^{1}$, Dương Thị Thủy ${ }^{2}$, Hồ Tú Cường ${ }^{2}$, \\ Trần Thị Bích $\mathrm{Nga}^{3}$ \\ ${ }^{1}$ Viện Hóa học các Hợp chất thiên nhiên, Viện HLKHCNVN, 18 Hoàng Quốc Việt, Hà Nội \\ ${ }^{2}$ Viện Công nghệ môi truoòng, Viện HLKHCNVN, 18 Hoàng Quốc Việt, Cầu Giấy, Hà Nội \\ ${ }^{3}$ Cục Khí tuợng thuỷ văn và Biến đổi khí hậu, 8 Pháo Đài Láng, Hà Nội \\ *Email: quynhltp@yahoo.com
}

Đến Tòa soạn: 23/4/2014; Chấp nhận đăng: 17/9/2014

\section{TÓM TẮT}

Chất lượng môi trường, đặc biệt là môi trường nước đang ngày càng được quan tâm. Bài báo trình bày kết quả quan trắc hàng tháng về hàm lượng kim loại nặng hòa tan trong nước sông Hồng tại Yên Bái, Hà Nội, Hòa Bình và Vụ Quang trong giai đoạn từ tháng 1 đến tháng 10 năm 2012. Kết quả quan trắc cho thấy hàm lượng một số kim loại nặng dạng hòa tan trong nước sông Hồng thay đổi trong khoảng rộng: $\mathrm{Cu}: 10-80 \mu \mathrm{g} / \mathrm{l} ; \mathrm{Zn}: 2-88 \mu \mathrm{g} / \mathrm{l}$; $\mathrm{Cr}: 0,2-5,1 \mu \mathrm{g} / \mathrm{l} ; \mathrm{Pb}: 2-$ $107 \mu \mathrm{g} / \mathrm{l} ; \mathrm{Cd}$ : : 2 - $12 \mu \mathrm{g} / \mathrm{l} ; \mathrm{Mn}: 2$ - $35 \mu \mathrm{g} / \mathrm{l} ; \mathrm{Fe}: 160$ - $950 \mu \mathrm{g} / \mathrm{l}$. Hàm lượng của hầu hết các kim loại nặng tại 4 vị trí quan trắc đều nằm trong giới hạn cho phép của Quy chuẩn Việt Nam đối với chất lượng nước mặt QCVN 08:2008/BTNMT. Tuy nhiên, tại một số thời điểm quan trắc, hàm lượng của một số kim loại như $\mathrm{Fe}, \mathrm{Cd}$ và $\mathrm{Pb}$ đã vượt quá giới hạn cho phép của Quy chuẩn Việt Nam. Các kết quả này chỉ ra rằng cần phải liên tục giám sát chất lượng nước sông để giảm thiểu những tác động bất lợi đến sức khỏe con người, cũng như tới hệ thủy sinh thái.

Tù khóa: ô nhiễm, chất lượng nước, kim loại nặng, sông Hồng.

\section{MỞ ĐÀ̀U}

Lưu vực sông Hồng có vị trí địa lí đặc biệt, đóng vai trò quan trọng trong sự phát triển kinh tế - xã hội của miền Bắc Việt Nam. Sông Hồng cung cấp nước cho các hoạt động sản xuất công nghiệp, nông nghiệp trong lưu vực, và đồng thời cung cấp nước sinh hoạt cho một số cộng đồng dân cư ven sông, bao gồm một số tỉnh đồng bằng. Tuy nhiên, song song với sự phát triển kinh tế trong lưu vực, ô nhiễm môi trường nước trong lưu vực là vấn đề cần quan tâm.

Kim loại nặng (KLN) là một trong những thông số ô nhiễm môi trường đáng được chú ý. Hàm lượng cao KLN trong môi trường đất và nước, theo chuỗi thức ăn, sẽ có ảnh hưởng đáng kể tới đời sống động, thực vật và con người. Một số KLN đóng vai trò là nguyên tố vi lượng cung cấp cho cơ thể con người và theo tiêu chuẩn WHO quy định trong nước uống như sau: $\mathrm{Cr} \leq 50$ $\mu \mathrm{g} / \mathrm{l} ; \mathrm{Cd} \leq 5 \mu \mathrm{g} / \mathrm{l} ; \mathrm{Mn} \leq 50 \mu \mathrm{g} / \mathrm{l} ; \mathrm{Pb} \leq 25 \mu \mathrm{g} / 1$ [1]. Nếu vượt quá ngưỡng quy định chúng sẽ được 
tích lũy và gây ảnh hưởng đến hệ thần kinh, gây độc cho các cơ quan trong cơ thể và đặc biệt với một số KLN có độc tính cao, chúng có thể gây độc ở mức vi lượng (như $\mathrm{Pb}, \mathrm{Cd}, .$.$) [1].$

Hàm lượng KLN trong nước sông chịu ảnh hưởng trực tiếp của các yếu tố tự nhiên và/hoặc do con người tạo ra. Các nguồn tự nhiên chính được kể đến như chế độ khí hậu - thủy văn, địa chất, địa mạo lưu vực liên quan đến khoáng chất và rửa trôi đất góp phần gia tăng hàm lượng KLN trong nước sông. Các nguồn cung cấp KLN do con người tạo ra chủ yếu có liên quan với nước thải công nghiệp và nước thải sinh hoạt, nước từ bãi rác, khai thác khoáng sản, rửa trôi phân bón hóa học ... (Hình 1) [2, 3]. Với mục đích sử dụng nước sông Hồng như hiện nay, vấn đề đặt ra là cần có các quan trắc, đánh giá chất lượng nước, đặc biệt là hàm lượng các kim loại trong môi trường nước sông.

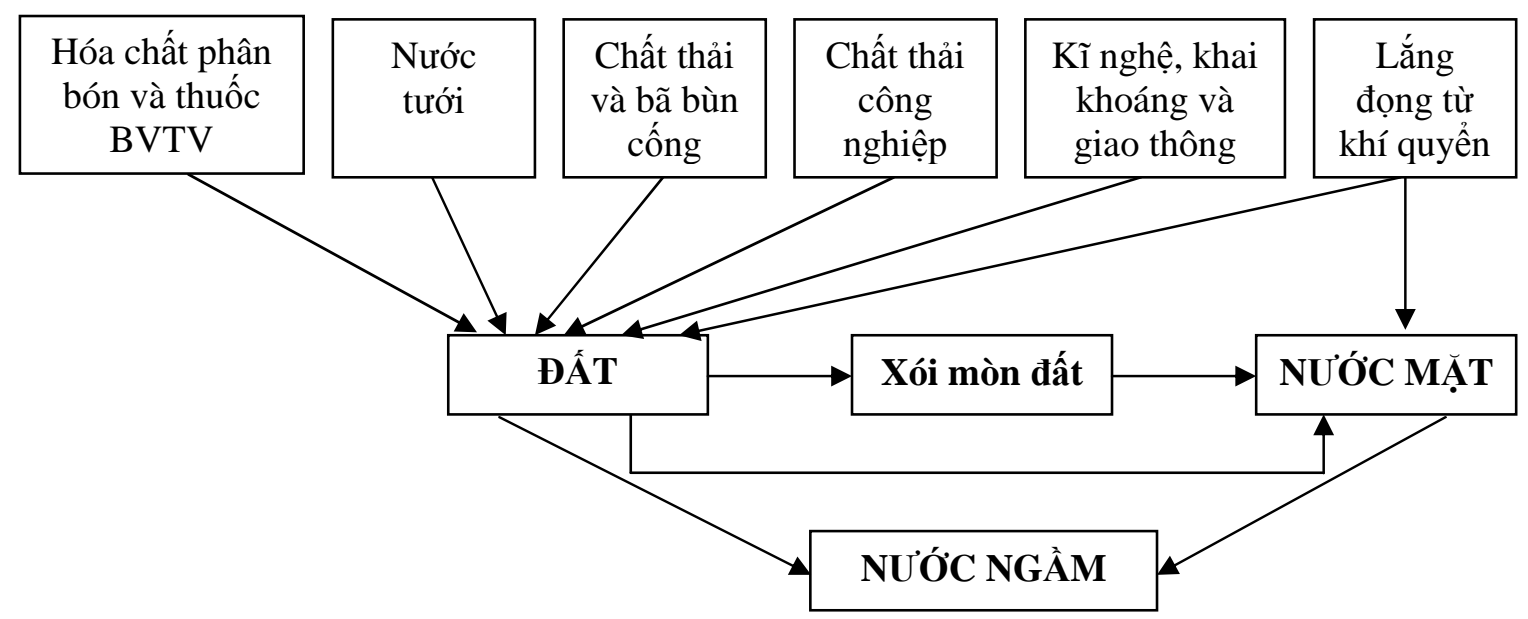

Hình 1. Ô nhiễm kim loại nặng do tác động của con người đối với đất và nước [4].

Bài báo này trình bày các kết quả bước đầu khảo sát hàm lượng một số $\mathrm{KLN}(\mathrm{Pb}, \mathrm{Cd}, \mathrm{Zn}$, $\mathrm{Mn}, \mathrm{Cr}, \mathrm{Fe}, \mathrm{Cu}$ ) trong môi trường nước hệ thống sông Hồng, đoạn chảy từ Yên Bái đến Hà Nội, trong giai đoạn 1/2012 - 10/2012. Kết quả đạt được góp phần đánh giá chất lượng nước sông nhằm sử dụng nguồn nước an toàn và hiệu quả cho các mục đích công - nông - ngư nghiệp và dân sinh.

\section{2. ĐỐI TƯợNG VÀ PHƯƠNG PHÁP NGHIÊN CÚU}

\section{1 Đối tượng nghiên cứu}

Sông Hồng là một trong chín hệ thống sông lớn ở Việt Nam có tổng diện tích lưu vực đạt $156.451 \mathrm{~km}^{2}$. Ba nhánh chính (Đà, Lô, Thao) ở phần thượng nguồn gặp nhau tại Việt Trì̀, tạo nên châu thổ sông Hồng. Lưu vực sông Hồng chịu ảnh hưởng của khí hậu nhiệt đới gió mùa với đặc trưng khí hậu nóng ẩm, mưa nhiều. Lượng mưa bình quân hàng năm dao động trong khoảng $1500-2000 \mathrm{~mm}$. Lưu lượng nước hệ thống sông Hồng vào mùa mưa (từ tháng 5 đến tháng 10 ) cao hơn so với mùa khô. Số liệu đo đạc lưu lượng nước hàng ngày trong năm 2012 của Viện Khí tượng, Thủy văn và Môi trường cho thấy lưu lượng nước trung bình tại các trạm thủy văn Yên Bái, Hòa Bình, Vụ Quang và Hà nội năm 2012 lần lượt là $560 \mathrm{~m}^{3} / \mathrm{s} ; 1453 \mathrm{~m}^{3} / \mathrm{s} ; 1160 \mathrm{~m}^{3} / \mathrm{s}$; và $2019 \mathrm{~m}^{3} / \mathrm{s}$. 
Trong lưu vực sông Hồng, dân số phân bố không đều với mật độ dân cư nhỏ hơn 100 người $/ \mathrm{km}^{2}$ ở vùng thượng nguồn và lớn hơn 1000 người $/ \mathrm{km}^{2}$ ở vùng đồng bằng [5]. Theo các tài liệu thống kê, trong vùng lưu vực, đất xám và đất phù sa chiếm chủ yếu $70 \%$; các loại đất khác như đất mặn, đất phèn, đất nâu đỏ, đất đá bột... có tỉ lệ nhỏ $(<5 \%)$. Về mặt sử dụng đất, đất rừng và đất đồng cỏ chiếm phần lớn ở vùng thượng nguồn lưu vực (34 \% và $24 \%$ tương ứng), đất trồng cây công nghiệp chiếm $10 \%$, đất trồng lúa chiếm $8 \%$ và đất đô thị chỉ chiếm phần rất nhỏ $(<1 \%)$. Sản xuất công nghiệp được phát triển trong thời gian gần đây với 6 ngành công nghiệp chính: cơ khí điện tử (15\%); chế biến lương thực- thực phẩm (20\%); dệt nhuộm (12\%); giấy - gỗ (13\%); hóa chất (10\%) và vật liệu xây dựng (29\%) [6]. Nguồn nước sông Hồng chịu tác động bởi các hoạt động sản xuất cồng - nông nghiệp cũng như khai thác khoáng sản trong lưu vực ngày một gia tăng, làm cho chất lượng nước sông Hồng ngày càng xấu đi theo không gian và thời gian [7].

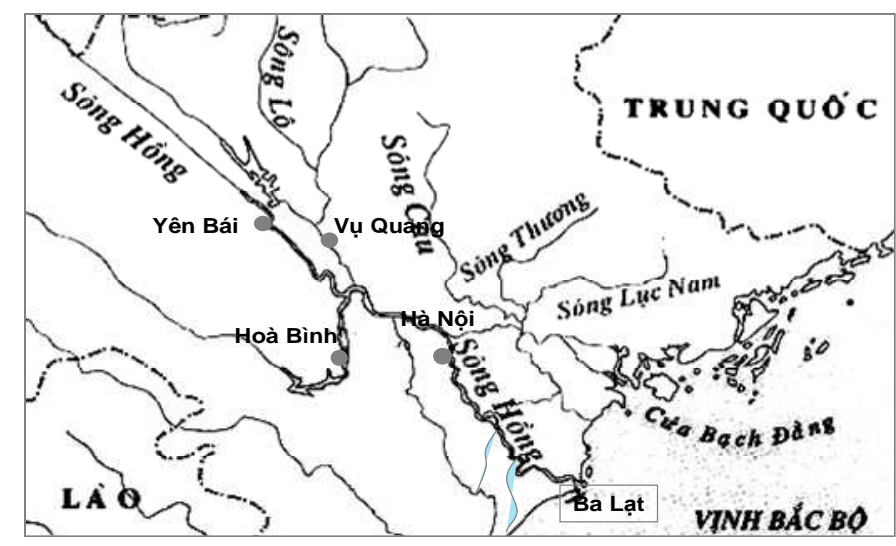

Hình 2. Sơ đồ các vị trí lấy mẫu trên hệ thống sông Hồng.

\subsection{Phương pháp nghiên cứu}

Thời gian và vị trí lấy mẫu: Các mẫu nghiên cứu được lấy hàng tháng trong thời gian từ tháng 1/2012 - 10/2012 tại 4 vị trí: trạm thuỷ văn Hòa Bình (sông Đà); trạm Vụ Quang (sông Lô); trạm Yên Bái (sông Thao) và trạm Hà Nội, trên nhánh chính sông Hồng (Hình 2).

Phuơng pháp lấy mẫu và bảo quản mẫu: Các mẫu nước mặt ở giữa dòng sông, được lấy theo tiêu chuẩn Việt Nam TCVN 6663-6: 2008. Các mẫu nước được lọc qua giấy lọc GF/F có kích thước lỗ $0,45 \mu \mathrm{m}$ để phân tích hàm lượng các KLN và được bảo quản trong chai thủy tinh tối màu, trữ lạnh ở $4{ }^{0} \mathrm{C}$, trong môi trường axit.

Phuoong pháp xác định: Các chỉ tiêu $\mathrm{pH}, \mathrm{DO}$, độ dẫn điện và độ đục được đo đạc trực tiếp tại hiện trường bằng máy đo nhanh đa chỉ tiêu WQC-22A (TOA, Nhật Bản). Hàm lượng các KLN được xác định bằng phương pháp so màu theo tiêu chuẩn Việt Nam trên máy DRELL 2800 (HACH, Mĩ) như sau: Cu: TCVN 4572 - 88; Zn: TCVN 4575 - 88; Cr: TCVN 6658 - 2000; Cd: TCVN 2664 - 78; Pb: TCVN 4573 - 88; Mn: TCVN 6002 - 1995 và Fe: TCVN 6177 1996. Các phép đo được lặp lại 3 lần và kết quả là giá trị trung bình.

\section{KẾT QUẢ VÀ THẢO LUẬN}

\subsection{Chỉ tiêu hóa lí}


Giá trị pH trung bình của các mẫu nước sông Hồng tại các điểm quan trắc dao động từ 6,7 8,4; hàm lượng oxy hòa tan dao động từ $3,42-6,06 \mathrm{mg} / \mathrm{l}$. Độ dẫn điện trung bình trạm thủy văn Yên Bái, Vụ Quang, Hòa Bình và Hà Nội đạt 166; 172; 164 và $176 \mu \mathrm{S} / \mathrm{cm}$ tương ứng. Độ đục giữa các trạm quan trắc có sự chênh lệch nhau khá lớn từ 1 - 309 NTU, trạm Hòa Bình có độ đục thấp nhất so với các trạm khác do sự vận hành của các hồ chứa Hòa Bình và Sơn La trên sông Đà.

\subsection{Hàm lượng một số kim loại nặng}

Kết quả quan trắc hàm lượng các KLN trong thời gian từ tháng 1 - tháng 10 năm 2012 tại 4 trạm thủy văn Yên Bái, Hòa Bình, Vụ Quang và Hà Nội được trình bày trong bảng 1 . Bảng 1 cho thấy, đa số hàm lượng các $\mathrm{KLN}(\mathrm{Pb}, \mathrm{Cd}, \mathrm{Zn}, \mathrm{Mn}, \mathrm{Cr}, \mathrm{Fe}, \mathrm{Cu})$ nằm trong giới hạn cho phép cột $\mathrm{A} 1$ của $\mathrm{QCVN}$ 08:2008/BTNMT, ngoại trừ một số $\mathrm{KLN}$ như $\mathrm{Cd}, \mathrm{Pb}$, và đặc biệt là $\mathrm{Fe}$ ở một vài thời điểm tại các trạm quan trắc đã vượt quá ngưỡng cho phép của quy chuẩn trên, được trình bày cụ thể dưới đây:

Bảng 1. Hàm lượng một số KLN dạng hòa tan ( $\mu \mathrm{g} / \mathrm{l})$ (giá trị trung bình; (giá trị nhỏ nhất - lớn nhất) và giá trị median) trong nước hệ thống sông Hồng giai đoạn 1/2012 - 10/2012.

\begin{tabular}{|c|c|c|c|c|c|}
\hline $\begin{array}{l}\text { Các chỉ } \\
\text { tiêu }\end{array}$ & Trạm Yên Bái & $\begin{array}{c}\text { Trạm Vụ } \\
\text { Quang }\end{array}$ & $\begin{array}{c}\text { Trạm Hoà } \\
\text { Bình }\end{array}$ & $\begin{array}{c}\text { Trạm Hà } \\
\text { Nội }\end{array}$ & $\begin{array}{c}\text { QCVN } \\
\text { o8:2008/BTNMT } \\
(\text { Cột A1 *) }\end{array}$ \\
\hline $\mathrm{Cu}$ & $\begin{array}{c}34 \\
(20-40) \\
33,5\end{array}$ & $\begin{array}{c}43 \\
(24-80) \\
39,0\end{array}$ & $\begin{array}{c}34 \\
(10-60) \\
35,0\end{array}$ & $\begin{array}{c}31 \\
(20-50) \\
30,0\end{array}$ & 100 \\
\hline $\mathrm{Zn}$ & $\begin{array}{c}29 \\
(3-62) \\
18,6\end{array}$ & $\begin{array}{c}31 \\
(2-87) \\
23,4\end{array}$ & $\begin{array}{c}25 \\
(5-88) \\
13,8\end{array}$ & $\begin{array}{c}31 \\
(5-88) \\
13,4\end{array}$ & 500 \\
\hline $\mathrm{Cr}$ & $\begin{array}{c}1,6 \\
(0,5-5,1) \\
1,1\end{array}$ & $\begin{array}{c}1,6 \\
(0,4-4,1) \\
1,5\end{array}$ & $\begin{array}{c}1,4 \\
(0,2-4,2) \\
0,9\end{array}$ & $\begin{array}{c}2,0 \\
(0,2-5,0) \\
1,3\end{array}$ & 10 \\
\hline $\mathrm{Pb}$ & $\begin{array}{c}8,0 \\
(2-13) \\
8,5\end{array}$ & $\begin{array}{c}8,0 \\
(3-17) \\
7,3\end{array}$ & $\begin{array}{c}12 \\
(2-68) \\
6,1\end{array}$ & $\begin{array}{c}15 \\
(2-107) \\
6,3\end{array}$ & 20 \\
\hline $\mathrm{Cd}$ & $\begin{array}{c}6 \\
(4-8) \\
5,0\end{array}$ & $\begin{array}{c}5 \\
(4-7) \\
4,8\end{array}$ & $\begin{array}{c}6 \\
(4-7) \\
5,2\end{array}$ & $\begin{array}{c}6 \\
(2-12) \\
6,0\end{array}$ & 5 \\
\hline Mn & $\begin{array}{c}13 \\
(5-35) \\
8,0\end{array}$ & $\begin{array}{c}10 \\
(5-19) \\
10,0\end{array}$ & $\begin{array}{c}10 \\
(2-19) \\
9,1\end{array}$ & $\begin{array}{c}11 \\
(7-18) \\
9,6\end{array}$ & - \\
\hline $\mathrm{Fe}$ & $\begin{array}{c}720 \\
(250-2760) \\
495\end{array}$ & $\begin{array}{c}530 \\
(170-750) \\
250\end{array}$ & $\begin{array}{c}530 \\
(170-2100) \\
280\end{array}$ & $\begin{array}{c}950 \\
(160-2370) \\
535\end{array}$ & 500 \\
\hline
\end{tabular}

*: Quy chuẩn 08:2008/BTNMT cột A1 quy định cho nguồn nước "Sử dụng tốt cho mục đích cấp nước sinh hoạt và các mục đích khác". 
Hàm lương Cu: tại 4 vị trí quan trắc biến đổi trong khoảng từ $10-80 \mu \mathrm{g} / \mathrm{l}$, trung bình đạt $35,5 \mu \mathrm{g} / \mathrm{l}$, hoàn toàn nằm trong giới hạn cho phép QCVN 08:2008/BTNMT, cột $\mathrm{A} 1(<100 \mu \mathrm{g} / \mathrm{l})$. Hàm lượng $\mathrm{Cu}$ trung bình cao nhất ghi nhận được tại trạm Vụ Quang và thấp nhất tại trạm Hà Nội. Hàm lượng $\mathrm{Cu}$ tại 4 trạm quan trắc trên sông Hồng gần với một số sông khác ở miền Bắc như sông Tô Lịch tại Nghĩa Đô $(10 \mu \mathrm{g} / \mathrm{l})$, tại cửa sông Đáy $(38 \mu \mathrm{g} / \mathrm{l})$, sông Sét $(10 \mu \mathrm{g} / \mathrm{l})$ [8], và nhỏ hơn so với sông Nhuệ $(151 \mu \mathrm{g} / \mathrm{l})$ [9]. Hàm lượng $\mathrm{Cu}$ tại 4 trạm thủy văn có sự khác biệt theo mùa, mùa khô có xu hướng cao hơn mùa mưa (Hình $3 \mathrm{a}$ ), gợi ý rằng $\mathrm{Cu}$ có thể có nguồn gốc từ các nguồn thải điểm (mỏ khai thác khoáng sản, nước thải công nghiệp... ) trong lưu vực.

Hàm lượng $Z n$ : biến đổi trong khoảng từ $2-88 \mu \mathrm{g} / \mathrm{l}$, trung bình đạt $29 \mu \mathrm{g} / \mathrm{l}$, luôn nằm trong giới hạn cho phép của QCVN 08:2008/BTNMT, cột A1 $(<500 \mu \mathrm{g} / \mathrm{l})$. Các giá trị cao nhất đạt được vào tháng $8 / 2012$ và thấp nhất vào tháng 4/2012 tại tất cả các vị trí quan trắc, ngoại trừ trạm Vụ Quang (Hình 3b). Các giá trị trung bình tại các trạm Yên Bái, Vụ Quang, Hòa Bình và Hà Nội lần lượt là $29 ; 31 ; 25$ và $31 \mu \mathrm{g} / \mathrm{l}$. Các giá trị này của sông Hồng so với một số sông khác không có sự khác biệt nhiều: sông Nhuệ (cầu Hà Đông) $20 \mu \mathrm{g} / \mathrm{l}$; sông Sét (cầu Sét) $30 \mu \mathrm{g} / \mathrm{l}$; cửa sông Đáy $50 \mu \mathrm{g} / \mathrm{l}$ [8]. Tuy nhiên, so với giá trị trung bình của sông Nhuệ (440 $\mu \mathrm{g} / \mathrm{l})$ thì nhỏ hơn rất nhiều lần [9]. Quan sát thấy gia tăng hàm lượng $\mathrm{Zn}$ trong nước sông Hồng vào các tháng 8,9 và 10 năm 2012, gợi ý rằng nguồn cung cấp chính $Z n$ cho nước sông Hồng đến từ nguồn thải phát tán (xói mòn đất đá trong lưu vực, rửa trôi từ canh tác đất nông nghiệp...) (Hình $3 b$ ).

Hàm luợng $C r$ : Trong nước sông Hồng, hàm lượng $\mathrm{Cr}$ thay đổi trong khoảng từ $0,2-5,1$ $\mu \mathrm{g} / \mathrm{l}$, trung bình đạt $1,7 \mu \mathrm{g} / \mathrm{l}$. Giá trị cao nhất được ghi nhận tại trạm Hà Nội $(5,1 \mu \mathrm{g} / \mathrm{l})$ vào tháng 2. Các giá trị quan trắc đều nằm trong giá trị cho phép của quy chuẩn Việt Nam $(<10 \mu \mathrm{g} / \mathrm{l})$. Tuy vậy, các giá trị này lớn hơn nhiều so với sông Nhuệ tại địa phận Cầu Diễn $(0,16 \mu \mathrm{g} / \mathrm{l})$, nhưng nhỏ hơn sông Tô Lịch đoạn chảy từ Hoàng Quốc Việt đến Ngã Tư Sở $(6,9 \mu \mathrm{g} / \mathrm{l})$ [8]. Hàm lượng Cr trong sông Hồng có sự khác biệt không đáng kể theo mùa, cao vào các tháng $1,2,7$ và 8 , thấp vào các tháng $3 \div 6$. (Hình $3 \mathrm{c}$ ). Các nguồn cung cấp $\mathrm{Cr}$ cho nước sông Hồng có thể từ nguồn thải điểm như nước thải công nghiệp (như sản xuất sơn, thuộc da, bột màu, thuốc nhuộm, khai thác và chế biến các kim loại ...), chất thải đô thị, hóa chất tẩy rửa...

Hàm lương $P b$ : dao động trong khoảng từ 2,0 -107 $\mu \mathrm{g} / \mathrm{l}$ tại 4 vị trí quan trắc, trung bình đạt $10,8 \mu \mathrm{g} / \mathrm{l}$. Giá trị trung bình $\mathrm{Pb}$ của sông Hồng gần với giá trị $\mathrm{Pb}$ của sông Hoàng Long tại bến Đế $(11,5 \mu \mathrm{g} / \mathrm{l})$, tại cửa sông Đáy $(8,1 \mathrm{mg} / \mathrm{l})$ [8], sông Tô Lịch đoạn chảy từ Hoàng Quốc Việt đến Ngã Tư Sở $(4,4 \mu \mathrm{g} / \mathrm{l})$, nhưng cao hơn sông Lừ tại Phương Liệt $(0,44 \mu \mathrm{g} / \mathrm{l})$ [8] và nhỏ hơn sông Nhuệ $(31 \mu \mathrm{g} / \mathrm{l})[9]$. Mặc dù hàm lượng trung bình $\mathrm{Pb}$ trong nước sông Hồng nhỏ hơn giá trị cho phép của quy chuẩn Việt nam $(<20 \mu \mathrm{g} / \mathrm{l})$, nhưng trong quá trình quan trắc, tại một số thời điểm, hàm lượng $\mathrm{Pb}$ vượt quá tiêu chuẩn cho phép $2 \div 5$ lần, trạm Hòa Bình vào tháng $1(68 \mu \mathrm{g} / \mathrm{l})$, và trạm Hà Nội vào tháng $3(107 \mu \mathrm{g} / \mathrm{l})$ (hình $3 \mathrm{~d})$. Ô nhiễm $\mathrm{Pb}$ trong nước sông Hồng có thể có nguyên nhân do nước thải sản xuất công nghiệp (ví dụ do nước thải của một số nhà máy sản xuất pin, hóa chất tại Việt Trì, nước thải sinh hoạt, các hoạt động của phương tiện giao thông vận tải sử dụng xăng pha chì, khai thác khoáng sản, lắng đọng khí quyển ...

Hàm lương Mn: dao động trong khoảng $2-35 \mu \mathrm{g} / \mathrm{l}$, trung bình đạt $11 \mu \mathrm{g} / \mathrm{l}$. Quy chuẩn Việt nam 08:2008/BTNMT chưa quy định giá trị cho hàm lượng Mn trong nước mặt. Hàm lượng Mn cao nhất đạt được vào tháng 4/2012 tại trạm Yên Bái (Hình 3e). Mn đi vào môi trường nước sông có thể do quá trình rửa trôi, xói mòn, do các chất thải công nghiệp luyện kim, acqui hoặc rửa trôi phân bón hoá học từ đất nông nghiệp. 

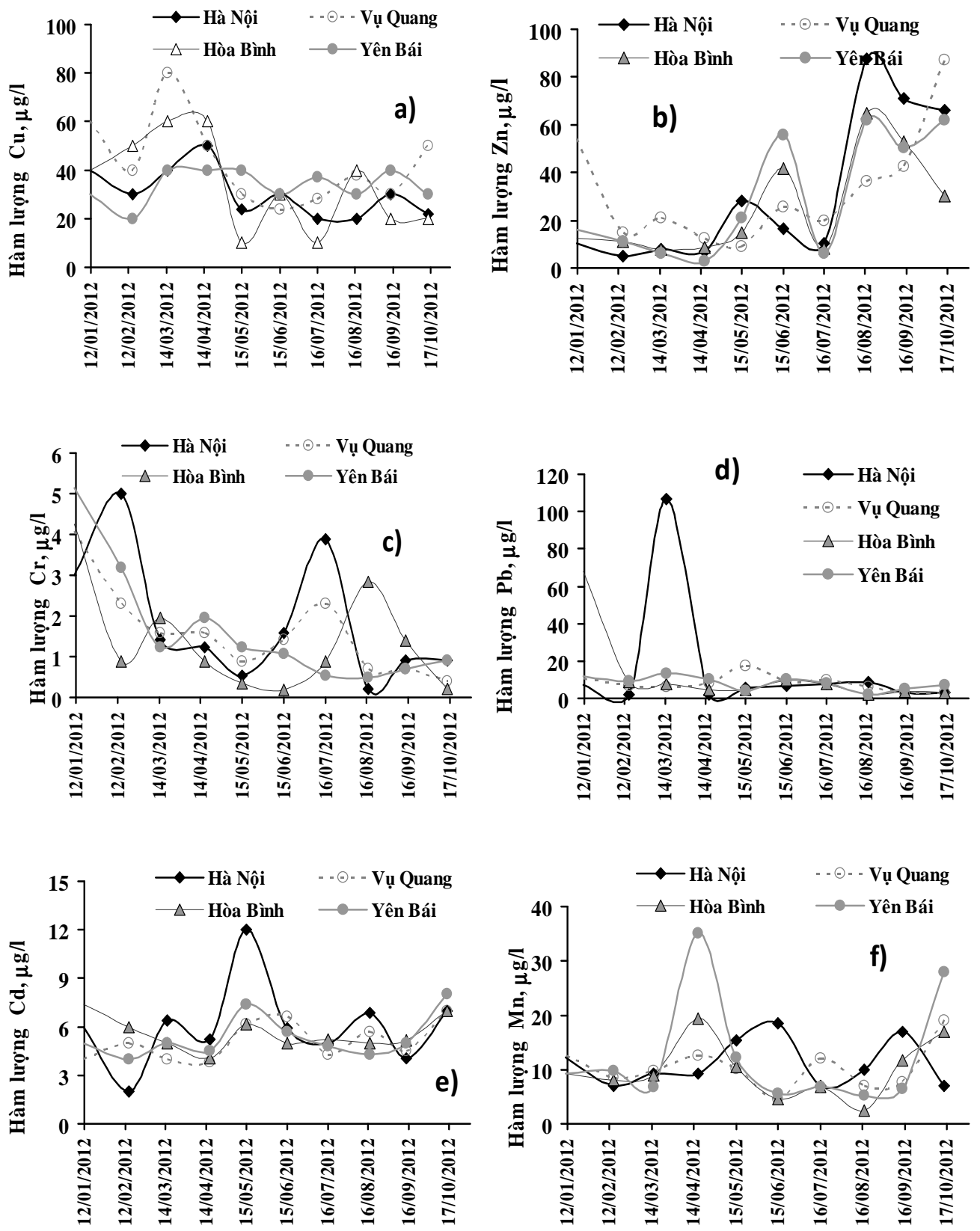

Hình 3. Hàm lượng một số kim loại nặng dạng hòa tan tại các trạm thủy văn lưu vực sông Hồng: a) Hàm lượng $\mathrm{Cu}$; b) Hàm lượng $\mathrm{Zn}$; c) Hàm lượng $\mathrm{Cr}$; d) Hàm lượng $\mathrm{Pb}$; e) Hàm lượng $\mathrm{Cd}$; f) Hàm lượng Mn.

Hàm lương $C d$ : trong khoảng từ $2,0-12,0 \mu \mathrm{g} / \mathrm{l}$, trung bình đạt $5,8 \mu \mathrm{g} / \mathrm{l}$ tại 4 vị trí quan trắc. Giá trị trung bình của 4 trạm thủy văn hầu như không có sự khác biệt $(5-6 \mu \mathrm{g} / \mathrm{l})$ theo các tháng quan trắc, đồng thời ít biến đổi tại hai trạm Hòa Bình và Vụ Quang, có sự biến đổi đồng điệu giữa hai trạm Yên Bái và Hà Nội (Hình $3 e$ ). Hàm lượng $\mathrm{Cd}$ trung bình và tại một số thời điểm ở các trạm vượt quá quy chuẩn cho phép $(5 \mu \mathrm{g} / \mathrm{l})$ : trạm Hòa Bình $(7 \mu \mathrm{g} / \mathrm{l})$ vào tháng 1 và tháng 10; trạm Vụ Quang (7 $\mu \mathrm{g} / \mathrm{l})$ vào tháng 6 và tháng 10; trạm Yên Bái (7 và $8 \mu \mathrm{g} / \mathrm{l})$ vào tháng 
5 và tháng 10 ; và tại trạm Hà Nội $(12$ và $7 \mu \mathrm{g} / \mathrm{l})$ vào tháng 5 và tháng 10 . Sự ô nhiễm này có thể gây ra do nước thải công nghiệp (ví dụ: ngành sản xuất thuốc nhuộm và các chất màu sơn, bột màu, men thủy tinh..,), do nước thải sinh hoạt, do rửa trôi, xói mòn từ đất canh tác nông nghiệp có phân bón dư thừa, do quá trình khai thác các mỏ kim loại hoặc do lắng đọng bụi khí quyển trong lưu vực sông Hồng. Tuy nhiên, các giá trị quan trắc trên sông Hồng trong nghiên cứu này vẫn nhỏ hơn so với hàm lượng Cd trên sông Nhuệ tại địa phận Cầu Diễn $(31 \mu \mathrm{g} / \mathrm{l})$ [9].

Hàm lương $F e$ : dao động trong khoảng từ 160 - $2760 \mu \mathrm{g} / 1$, trung bình đạt $680 \mu \mathrm{g} / \mathrm{l}$. Hàm lượng trung bình $\mathrm{Fe}$ toàn hệ thống sông Hồng, cũng như trung bình tại trạm Hà Nội $(720 \mu \mathrm{g} / \mathrm{l})$, Yên Bái $(950 \mu \mathrm{g} / \mathrm{l})$ và tại một số thời điểm ở các trạm quan trắc đã vượt tiêu chuẩn cho phép QCVN 08:2008/BTNMT, cột $\mathrm{A} 1(<500 \mu \mathrm{g} / \mathrm{l})$ từ 1-5 lần. Hàm lượng Fe có xu hướng tăng cao trong mùa mưa, điều này cho thấy liên quan đến nguồn thải điểm và nguồn thải phát tán từ khai khoáng, phân bón dư thừa, nước thải sinh hoạt, do xói mòn cơ học từ địa chất tự nhiên trên toàn bộ lưu vực sông. Kết quả quan trắc này cũng phù hợp với báo cáo kết quả phân tích của Trung tâm Quan trắc môi trường và Cục Kiểm soát ô nhiễm Lào Cai [10]: nước sông Hồng tại Lào Cai bị ô nhiễm Fe
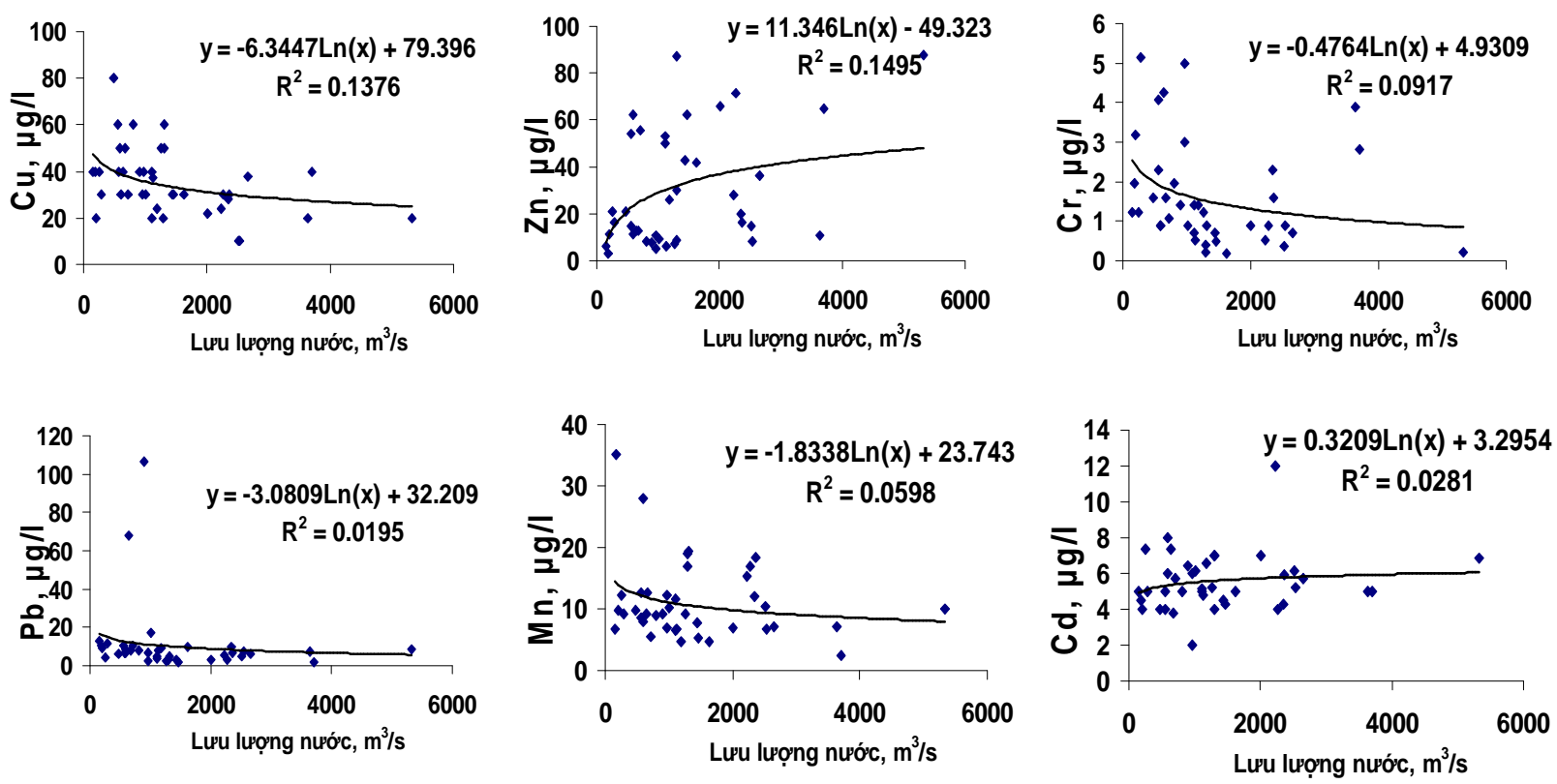

Hình 4. Mối quan hệ giữa hàm lượng một số kim loại nặng và lưu lượng nước của hệ thống sông Hồng giai đoạn 1/2012 - 10/2012.

Hình 4 biểu diễn mối quan hệ giữa hàm lượng các kim loại quan trắc với lưu lượng nước sông Hồng tại 4 trạm thủy văn. Có thể thấy hàm lượng các KLN được quan trắc không có xu hướng biến đổi rõ rệt theo lưu lượng nước sông, phản ánh nguồn gốc đa dạng của KLN trong nước sông, bao gồm cả nguồn gốc tự nhiên và nguồn gốc từ các hoạt động của con người trong lưu vực.

Trên thế giới, đã có nhiều nghiên cứu về hàm lượng các KLN dạng hòa tan trong nước sông (Bảng 2). Bảng 2 cho thấy hàm lượng trung bình của một số KLN dạng hòa tan trong nước sông Hồng thấp hơn nhiều so với sông Kasardi (Mumbai, Ân Độ), nơi chảy qua vùng sản xuất công 
nghiệp. Các giá trị KLN của sông Hồng rất gần với một số sông trên thế giới như sông Han (Trung Quốc), sông Lerma (Mexico) nhưng vẫn lớn hơn so với hàm lượng trung bình KLN được tìm thấy trong các dòng sông trên thế giới [11]. Hàm lượng một số KLN như $\mathrm{Cd}, \mathrm{Pb}, \mathrm{Fe}$ trong nước sông Hồng tại một số thời điểm ở các trạm quan trắc vượt quá giới hạn cho phép của QCVN 08-2008/ BTNMT cột $\mathrm{A} 1$. Sự ô nhiễm này có thể gây ra do chất thải và nước thải từ các khu công nghiệp, canh tác nông nghiệp, chăn nuôi và các làng nghề, khai thác khoáng sản... trong lưu vực và do các yếu tố tự nhiên của lưu vực (địa chất, chế độ khí hậu - thủy văn...).

Bảng 2. Hàm lượng trung bình một số kim loại nặng dạng hòa tan trong một số sông trên thế giới.

\begin{tabular}{|c|c|c|c|c|c|c|c|c|}
\hline \multirow{2}{*}{$\begin{array}{l}\text { Tên sông } \\
\text { (Tên nước) }\end{array}$} & \multicolumn{7}{|c|}{ Hàm lượng một số kim loại nặng, $\mu \mathrm{g} / \mathrm{l}$} & \multirow{2}{*}{ Tác giả } \\
\hline & $\mathrm{Cu}$ & $\mathrm{Zn}$ & $\mathrm{Cr}$ & $\mathrm{Pb}$ & $\mathrm{Cd}$ & $\mathrm{Mn}$ & $\mathrm{Fe}$ & \\
\hline $\begin{array}{l}\begin{array}{l}\text { Danube } \\
\text { (Rumani) }\end{array} \\
\end{array}$ & 2,3 & 0,39 & - & 0,0168 & 0,0131 & 1,04 & 1,12 & $\begin{array}{l}\text { Guieu \& cs, } \\
1998 \text { [12] }\end{array}$ \\
\hline $\begin{array}{l}\text { Upper } \\
\text { Vistula } \quad(B a \\
\text { Lan) }\end{array}$ & $\begin{array}{c}0,90- \\
90,0\end{array}$ & $\begin{array}{l}16,2- \\
168,7\end{array}$ & $\begin{array}{c}0,61- \\
2,94\end{array}$ & $\begin{array}{l}0,8- \\
80,7\end{array}$ & $\begin{array}{c}0,60- \\
0,73\end{array}$ & $\begin{array}{c}5,3- \\
583,8\end{array}$ & - & $\begin{array}{l}\text { Guéguen \& } \\
\text { Dominik } \\
\text { [2003] [13] }\end{array}$ \\
\hline $\begin{array}{l}\text { Lerma } \\
\text { (Mexico) }\end{array}$ & $10-40$ & - & $5-19$ & $3-14$ & - & $9-298$ & $\begin{array}{l}98- \\
984 \\
\end{array}$ & $\begin{array}{l}\text { Zarazua \& } \\
\text { cs., } 2006[3]\end{array}$ \\
\hline $\begin{array}{l}\text { Asunle } \\
\text { (Nigeria) }\end{array}$ & $\begin{array}{l}130- \\
390\end{array}$ & $\begin{array}{l}430- \\
1000\end{array}$ & - & $5-17$ & $3-6$ & $\begin{array}{l}300- \\
1390\end{array}$ & - & $\begin{array}{l}\text { Ogunfowokan } \\
\& \text { cs., } 2013 \\
\text { [14] }\end{array}$ \\
\hline $\begin{array}{l}\text { Sabarmati } \\
\text { (Ấn Độ) }\end{array}$ & $0,7-14,2$ & $\begin{array}{c}5,0- \\
146,0\end{array}$ & $\begin{array}{l}1,01- \\
4,98\end{array}$ & $\begin{array}{c}0,3- \\
11,65\end{array}$ & $\begin{array}{c}0,005- \\
0,042\end{array}$ & - & - & $\begin{array}{l}\text { Gandhi, } 2013 \\
\text { [15] }\end{array}$ \\
\hline $\begin{array}{l}\text { Kasardi (Ấn } \\
\text { Độ) }\end{array}$ & $\begin{array}{l}8100- \\
44300\end{array}$ & $\begin{array}{l}12900- \\
16700\end{array}$ & $\begin{array}{c}15200 \\
-19100\end{array}$ & $\begin{array}{l}8600- \\
33900\end{array}$ & $\begin{array}{c}12200- \\
18400\end{array}$ & - & $\begin{array}{l}7800- \\
13700\end{array}$ & $\begin{array}{l}\text { Lokhande \& } \\
\text { cs., } 2011 \text { [16] }\end{array}$ \\
\hline $\begin{array}{l}\text { Han (Trung } \\
\text { Quốc) }\end{array}$ & 13,4 & - & 8,14 & 9,26 & 2,34 & 30,7 & 30,64 & $\begin{array}{l}\text { Li \& Zhang, } \\
2010 \text { [17] }\end{array}$ \\
\hline Sông Hồng* & 31 & 31 & 2,0 & 15 & 6 & 11 & 950 & $\begin{array}{l}\text { Nghiên cứu } \\
\text { này }\end{array}$ \\
\hline $\begin{array}{l}\text { Trung bình } \\
\text { sông thế giới }\end{array}$ & 1,48 & 0,60 & 0,70 & 0,08 & 0,08 & 34 & 66 & $\begin{array}{l}\text { Viersa \& cs, } \\
2009[11]\end{array}$ \\
\hline
\end{tabular}

*: giá trị trung bình tại trạm Hà Nội, trên nhánh chính sông Hồng, sau hợp lưu của các sông Thao - Đà - Lô, giai đoạn $1 / 2012-10 / 2012$.

Trong lưu vực sông Hồng, phát triển sản xuất công nghiệp $(\mathrm{CN})$ thời gian gần đây đã và đang có ảnh hưởng xấu đến chất lượng nước sông, trong đó có hàm lượng các KLN [18]. Vùng thượng nguồn phát triển ngành $\mathrm{CN}$ khai khoáng, trong đó phải kể đến một số mỏ khai thác khoáng sản ở vùng thượng nguồn Trung Quốc và mỏ Apatit ở Lào Cai. Các khu công nghiệp tập trung, trong đó có khu $\mathrm{CN}$ Việt Trì, có khối lượng nước thải lớn vào sông Hồng (chỉ tính khối lượng nước thải $\mathrm{CN}$ của 28 nhà máy, doanh nghiệp có nguy cơ gây ô nhiễm đã là 102.000 $\mathrm{m}^{\dot{3}} /$ ngày). Bảy tỉnh vùng đồng bằng sông Hồng (Hà Nội, Bắc Ninh, Vĩnh Phúc, Quảng Ninh, Hải Phòng, Hải Dương và Hưng Yên) có tổng lượng nước thải công nghiệp đạt $155.055 \mathrm{~m}^{3} / \mathrm{ngày}$ [18]... Và như vậy, nếu nước thải không được xử lí triệt để, sẽ gây ảnh hưởng không nhỏ đến chất lượng nước sông. Vấn đề quản lí và xử lí nước thải không chặt chẽ của các cơ quan chức 
năng liên quan cũng gián tiếp góp phần làm gia tăng hàm lượng kim loại trong môi trường nước. Nguồn gây ô nhiễm KLN khác có thể kể tới trong lưu vực sông Hồng là gia tăng sử dụng phân bón hóa học trong nông nghiệp. Với diện tích đất canh tác lớn trong lưu vực, khối lượng phân bón hóa học đã và đang được sử dụng là lớn. Hiện nay, lượng phân bón hóa học sử dụng trên 1 ha lên tới 120-180 kg/năm, tăng gấp 4 lần so với hai thập niên trước đây trên cả hai địa phận Trung Quốc và Việt Nam [7]... Như đã đề cập ở trên, sự tích lũy của các KLN trong môi trường đất canh tác nông nghiệp và qua quá trình rửa trôi, ảnh hưởng tới nước mặt, không chỉ ảnh hưởng tới sự phát triển của các loại cây trồng mà nghiêm trọng hơn, nó ảnh hưởng tới sức khỏe của con người cũng như các loài động vật thông qua chuỗi thức ăn. Canh tác nông nghiệp gây ô nhiễm KLN trong môi trường đất và nước đã được quan trắc trong nhiều nghiên cứu trước đây $[2,19,20,21]$.

\section{KẾT LUẬN}

Các kết quả quan trắc bước đầu hàm lượng một số KLN trong nước sông Hồng tại 4 trạm thủy văn trong giai đoạn tháng 1/2012 - 10/2012 đã cho thấy đa số hàm lượng các KLN $(\mathrm{Cu}, \mathrm{Zn}$, $\mathrm{Cr}, \mathrm{Mn}, \mathrm{Pb}, \mathrm{Fe}$ ) trong nước sông Hồng có sự biến đổi theo mùa không rõ rệt. Hàm lượng các KLN trong nước sông Hồng biến đổi trong khoảng rộng: $\mathrm{Cu}$ : $10-80 \mu \mathrm{g} / \mathrm{l} ; \mathrm{Zn}$ : $2-88 \mu \mathrm{g} / \mathrm{l} ; \mathrm{Cr}$ : 0,2 - 5,1 $\mu \mathrm{g} / \mathrm{l}$; hàm lượng $\mathrm{Pb}: 2$ - $107 \mu \mathrm{g} / \mathrm{l} ; \mathrm{Cd}$ : 2 - $12 \mu \mathrm{g} / \mathrm{l}$; hàm lượng $\mathrm{Mn}$ : 2 - $35 \mu \mathrm{g} / \mathrm{l}$; hàm lượng Fe: 160 - $950 \mu \mathrm{g} / \mathrm{l}$. Hàm lượng trung bình KLN trong nước sông Hồng tại 4 điểm quan trắc chủ yếu nằm trong giới hạn cho phép của Quy chuẩn QCVN 08:2008/BTNMT cột $\mathrm{A} 1$. Tuy nhiên, tại một số thời điểm quan trắc, hàm lượng kim loại như $\mathrm{Fe}, \mathrm{Cd}$ và $\mathrm{Pb}$ đã vượt quá giá trị cho phép. Kết quả của nghiên cứu bước đầu cũng chỉ ra KLN trong nước sông Hồng có nguồn gốc đa dạng bao gồm cả nguồn gốc tự nhiên và do các hoạt động của con người trong lưu vực. Bên cạnh các yếu tố tự nhiên như đia chất, chế độ khí hậu -thủy văn, các hoạt động của con người như gia tăng sản xuất công nghiệp, đô thị hóa mà không có các hệ thống xử lí hoặc hệ thống xử lí nước thải hoạt động không hiệu quả, gia tăng phân bón trong canh tác nông nghiệp, khai thác khoáng sản, các hoạt động của các phương tiện giao thông... đã và đang có ảnh hưởng tới chất lượng nước sông, trong đó có các KLN.

Do quan trắc thấy sự gia tăng hàm lượng một số $\mathrm{KLN}(\mathrm{Cd}, \mathrm{Pb}, \mathrm{Fe})$ dạng hòa tan trong nước sông, và với nhu cầu sử dụng nước sông như hiện nay, cần phải liên tục giám sát chất lượng nước sông để giảm thiểu những tác động bất lợi đến sức khỏe con người, cũng như tới hệ thủy sinh thái. Đồng thời cần có các biện pháp tích cực ngăn chặn các nguồn gây ô nhiễm KLN cho nước sông Hồng.

Lòi cảm ơn. Nghiên cứu này được hoàn thành trong khuôn khổ đề tài IFS W4210-2 và đề tài ARCP2013_06CMY_Quynh. Tập thể tác giả chân thành cảm ơn Quỹ Khoa học Quốc tế (IFS) và tổ chức Mạng lưới Châu Á - Thái Bình Dương nghiên cứu những biến đổi toàn cầu (APN - NSF) đã tài trợ kinh phí thực hiện.

\section{TÀI LIỆU THAM KHẢO}

1. WHO. - Guidelines for drinking water quality. The $4^{\text {th }}$ edition. www.who.int/water sanitation health/publications/2011/dwq guidelines/en/index.h tml , 2011.

2. Sinha S., Gupta A. K., Bhatt K., Pandey K., Rai U. N., and Singh K. P. - Distribution of metals in the edible plants grown at Jajman, Kanpur (Indian) receiving treated tannery 
wastewater: relation with physico-chemical properties of the soil, Environmental Monitoring and Assessment 115 (2006) 1-22.

3. Zarazua G., Ávila-Pérez P., Tejeda S., Barcelo-Quintal I., Martínez T. - Analysis of total and dissolved heavy metals in surface water of a Mexican polluted river by total reflection X-ray fluorescence spectrometry. Spectrochimica Acta Part B 61 (2006) 1180-1184.

4. Singh B. R. and Steinnes E. - Soil and water contamination by heavy metals. In Soil Process and Water Quality (Lal R. and Stewart B.A. eds.), Lewis Publisher, Boca Raton, FL, USA, 1994, pp. 233-270.

5. Le Thi Phuong Quynh, Billen G., Garnier J. Théry S., Ruelland D., Nghiem X. A., Chau V. M. - Nutrient (N, P, Si) transfers in the subtropical Red River system (China and Vietnam): Modelling and budget of nutrient sources and sinks. Journal of Asian Earth Sciences 37 (2010) 259-274.

6. Vũ Hữu Hiếu, Lê Thị Phương Quỳnh, Dương Thị Thuỷ và Hồ Tú Cường - Bước đầu xác định hàm lượng silic hoà tan trong nước thải sản xuất công nghiệp trong lưu vực sông Hồng, Tạp chí Khoa học và Công nghệ 49 (3A) (2011) 99-105.

7. Le Thi Phuong Quynh, Gilles B., Garnier J., Chau Van Minh - Long-term biogeochemical functioning of the Red River (Vietnam): past and present situations, Regional Environmental Change 15 (2015) 329-339.

8. Nguyen Thai Lai \& cs. - Day/Nhue River Basin Pollution Sources Study: Improving Water Quality in the Day/Nhue River Basin, Vietnam: Capacity Building and Pollution Sources Inventory. The report prepared by ICEM - the International Centre for Environmental Management, 2007, tr. 155.

9. Trung tâm quan trắc môi trường, Tổng cục Môi trường - Quan trắc môi trường nước lưu vực sông Nhuệ Đáy năm 2010, 2010, tr.89.

10. Sở Tài nguyên và Môi trường tỉnh Lào Cai - Quan trắc, đánh giá hiện trạng nước sông Hồng đoạn chảy vào Lào Cai, 2011.

11. Viersa J., Dupré B. and Gaillardet J. - Chemical composition of suspended sediments in World Rivers: New insights from a new database. Science of total environment $\mathbf{4 0 7}$ (2009) 853-868.

12. Guieu C., Martin J. M., Tankéré S. P. C., Mousty F., Trincherini P., Bazot M. and Dai M. H. - On trace metal geochemistry in the Danube River and Western, Estuarine, Coastal and Shelf Science 4 (47) (1998) 471-485.

13. Guéguen C. and Dominik J. - Partitioning of trace metals between particulate, colloidal and truly dissolved fractions in a polluted river: the Upper Vistula River (Poland). Applied Geochemistry 18 (2003) 457-470.

14. Ogunfowokan A. O., Oyekunle J. A. O., Olutona G. O., Atoyebi A. O., and Lawal A. Speciation Study of Heavy Metals in Water and Sediments from Asunle River of the Obafemi Awolowo University, Ile-Ife, NigeriaInternational, Journal of Environmental Protection 3 (3) (2013) 6-16.

15. Gandhi T. K. - A study of dissolved heavy metals in Sabarmati River, Gujarat, India. Gra Global research analysis 2 (5) (2013) 10-11.

16. Lokhande R. S., Singare P. U., Pimple D. S. - Pollution in Water of Kasardi River Flowing along Taloja Industrial Area of Mumbai, India, World Environment 1 (1) (2011) 6-13. 
17. Li S and Zhang Q. - Spatial characterization of dissolved trace elements and heavy metals in the upper Han River (China) using multivariate statistical techniques, Journal of Hazardous Materials 176 (2010) 579-588.

18. Bộ Tài nguyên và Môi trường - Báo cáo Môi trường quốc gia 2009. Môi trường khu công nghiệp Việt Nam, 2009, tr.106.

19. Maqsud N. M. - Ô nhiễm môi trường nước ở vùng nội và ngoại ô thành phố Hồ Chí Minh nhận biết qua lượng kim loại nặng tích tụ trong nước và bùn của các kênh mương, Tạp chí Khoa học đất 10 (1998)162-168.

20. Mwegoha W. J. S. and Kihampa C. - Heavy metal contamination in agricultural soils and water in Dar es Salaam city, Tanzania, African Journal of Environmental Science and Technology 4 (11) (2010) 763-769.

\title{
ABSTRACT \\ PRELIMINARY RESULTS ON SOME HEAVY METAL CONTENTS IN THE RED RIVER SYSTEM
}

\author{
Nguyen Thi Bich Ngoc $^{1}$, Le Thi Phuong Quynh ${ }^{1, *}$, Nguyen Thi Mai Huong ${ }^{1}$, \\ Nguyen Bich Thuy ${ }^{1}, \mathrm{Vu}$ Duy An ${ }^{1}$, Duong Thi Thuy ${ }^{2}, \mathrm{Ho}$ Tu Cuong ${ }^{2}$, \\ Tran Thi Bich Nga ${ }^{3}$ \\ ${ }^{1}$ Institute of Natural Products Chemistry, VAST,18 Hoang Quoc Viet, Hanoi \\ ${ }^{2}$ Institute of Environmental Technology, VAST, 18 Hoang Quoc Viet, Hanoi \\ ${ }^{3}$ Department of Meteorology, Hydrology and Climate Change, \\ Ministry of Natural Resources and Environment, 8 Phao Dai Lang, Hanoi \\ *Email:quynhltp@yahoo.com
}

Environment quality, especially aquatic environment is increasingly being interested. This paper presents the initial results of dissolved heavy metal of the monthly observations for the period from January to October 2012 at Yen Bai, Ha Noi, Hoa Binh and Vu Quang stations in the Red River system. The monitoring results showed that the heavy metal concentrations in the Red River water varied in a high range: $\mathrm{Cu}: 10-80 \mu \mathrm{g} / \mathrm{l} ; \mathrm{Zn}: 2-88 \mu \mathrm{g} / \mathrm{l} ; \mathrm{Cr}: 0.2-5.1 \mu \mathrm{g} / \mathrm{l} ; \mathrm{Pb}$ : 2 - $107 \mu \mathrm{g} / \mathrm{l}$; Cd: : 2 - $12 \mu \mathrm{g} / \mathrm{l}$; Mn: 2 - $35 \mu \mathrm{g} / \mathrm{l}$; Fe: 160 - $950 \mu \mathrm{g} / \mathrm{l}$. Most of the mean values of heavy metal contents at the four monitoring sites were lower than the ones of the Vietnamese standard limits for surface water quality, QCVN 08:2008/BTNMT. However, at several time during the observation period, the contents of some heavy metals such as $\mathrm{Fe}, \mathrm{Cd}$ and $\mathrm{Pb}$ exceeded the Vietnamese standard limits. The results showed that the water quality of the Red River needs more be frequently and systhematically observed.

Keywords: pollution, water quality, heavy metals, Red River. 